Sarah Knight, ${ }^{1}$ Karl Nunkoosing, Aldert Vrij, and Julie Cherryman

\title{
Using Grounded Theory to Examine People's Attitudes Toward How Animals are Used
}

\section{ABSTRACT}

This study uses qualitative methodology to examine why people have different attitudes toward different types of nonhuman animal use. Seventeen participants took part in a semi-structured interview. The study used Grounded Theory to analyze the interviews and developed a model that consists of 4 major themes: (a) "attitudes toward animals,” (b) "knowledge of animal use procedures,” (c) "perceptions of choice,” and (d) "cost-benefit analysis." The findings illustrate that cognitive processing, characteristics of the species of animal being used, and the type of animal use can all influence attitudes toward animal use. Because previous research has focused on participant variables such as age and gender to explain variance in attitudes toward animal use (Furnham \& Pinder, 1990; Kellert \& Berry, 1981) and measured attitudes toward animal use in general (rather than distinguishing between different types of use) (Armstrong \& Hutchins, 1996), these findings can add to knowledge of people's views on animal use. This paper discusses how such views may be justified and maintained.

The present study used in-depth interviews that allowed participants to explore their views with greater freedom than is possible in questionnaire studies, in order to address why people have different views toward different types of nonhuman animal use. “Animal use” refers to a range of practices that involve humans using nonhuman animals, such as cosmetics testing on animals, hunting animals for sport, and farming. Yet, while people often hold different views toward different types of animal use (Knight, Vrij, Cherryman, \& Nunkoosing, 2003; Plous, 1993), research has continued to measure attitudes toward animal use in general (Armstrong \& Hutchins, 1996; Matthews \& Herzog, 1997), that is as one unidimensional construct rather than distinguishing between different types of animal use. Furthermore, while most studies have focused on participant characteristics (gender and age) to explain variations in attitudes (Furnham \& Pinder, 1990; Kellert \& Berry, 1981), we argue that factors relating to the species of animal and type of animal use also might influence people's views on this subject. For although people often may express generalized attitudes about whole classes of things, people, places, and events, they also modify these attitudes (and their accompanying behavior), according to specific contexts as demonstrated in the classic LaPiere (1934) study. Thus, animal use is not a unitary concept because it relates to many different aspects of human lives and their relationships with animals. A vegetarian with diabetes may still rely on insulin made from animal sources. 


\section{Belief in Animal Mind}

People hold different attitudes toward animal use depending on the species of animal to be used (Driscoll, 1992; Herzog \& Galvin, 1997), and the basis of this discrimination often depends on where the animal in question was perceived to be on the phylogenetic scale, that is in terms of their perceived mental abilities. "Belief in animal mind" (BAM) is the term used to describe people's belief in the mental abilities of animals. Do we believe that animals are self-aware, capable of solving problems, or experiencing emotions such as fear and sadness? BAM is a consistent predictor of attitudes to animal use (Hills, 1995; Knight et al., 2003). BAM negatively correlates with support for animal use while positively correlating with concern for animal welfare and humane behavior toward animals (Broida, Tingley, Kimball, \& Miele, 1993), and empathy toward other humans and animals (Hills, 1995).

\section{Why Use Qualitative Methodology?}

People often do not have great insight into their attitudes and beliefs concerning animal use (Pifer, Shimizu, \& Pifer, 1994); thus, it is important that research methods encourage participants to think about, and verbalize, their views (Hills, personal communication, January, 2002). Also, quantitative methodology examines only constructs generated by the researcher (thus, data and understanding is constrained to such pre-conceived constructs), whereas qualitative methods encourage participants to introduce the factors that they perceive to be important and relevant, allowing new constructs to emerge that are not constrained by the researcher. The present study uses qualitative methodology, not as an antithesis or alternative to quantitative methods but to complement quantitative research (Bauer, Gaskell, \& Allum, 2002).

Herzog (1993) proposed that qualitative methodology can enable us to understand the psychology behind the complexities of human-animal relationships, and such methods can enable researchers to create or develop new theories in areas of research where there is little existing knowledge (Rennie, Phillips, \& Quartaro, 1988). Thus, the contemporary version of Grounded Theory (Strauss \& Corbin, 1991) was used to develop a model that explains why people have different attitudes toward different types of animal use.

\section{Method and Analysis}

\section{Participants}

Nine men and eight women, aged 22-65 years, first took part in a questionnaire study about animal use and belief in animal mind and were interviewed afterward about why they might have different attitudes toward different types of animal use. ${ }^{2}$ The 17 participants represented the number of participants needed to reach theoretical saturation. This refers to the stage of data collection when new issues and ideas cease to emerge. 


\section{The Interviews}

Each in-depth interview followed a flexible format that allowed all persons to explore fully their ideas about animal use and their relationships with animals. The first author interviewed all participants. Each interview started by asking whether the participant held different attitudes toward different types of animal use and, if so, why this was the case. In keeping with the principles of theoretical sampling (Strauss \& Corbin, 1991), new issues were included in the interview protocol as they arose, to be used in subsequent interviews. These included topics such as farming, knowledge of animal use, whether participants considered there to be alternatives to using animals, the perceived costs and benefits of animal use, physical characteristics of animals, and attitudes and beliefs concerning birds, fish, and farm animals. Participants were encouraged to lead the interview and discuss issues that they perceived as important and relevant. Each interview took between 45-90 minutes.

\section{Preparation for Analysis}

All interviews were transcribed verbatim, with double spacing and wide margins for notes during coding; this resulted in 274 pages of transcripts. Each participant was given a number code, and each line of the text was numbered to facilitate location and indexing when necessary. (Nunkoosing \& Phillips, 1999).

\section{Overview of Analysis Techniques}

The Grounded Theory method of constant comparative analysis was employed to analyze the transcripts (Glaser \& Strauss, 1967; Strauss \& Corbin, 1990; Turner, 1981). Each transcript was read several times; then each word, line, and paragraph was examined to code text into smaller chunks (“open coding”). Each chunk was examined with the question, "what does this represent?” in mind, and each incident was compared with those before and after it. When all the text had been "chunked" and allocated descriptive codes, the codes were grouped into categories; similarities, differences, relationships, and patterns were noted as they emerged. This required the reading and re-reading of transcripts, and memos of issues and ideas that emerged throughout the process were recorded. Such memos kept in the form of a manuscript, together with notes in the margins of the transcripts, provided the basis of the write-up of results. A "paper trail” from data collection to analysis was kept.

The process of interpretation by the researchers was guided by asking questions such as what does this represent; why is this a representation of the event/concept/idea and no other; and how else does this participant represent this idea. Thus, interpretation is a loose, two-part process. First, coding, noting, and categorizing data may be seen as constituting the analysis part of the process that relies on the researcher's skill at identifying those aspects that potentially might represent a participant's theory about the topic of this study. The second part of interpretation seeks to demonstrate understanding of the world from the perspective and position of the participant. That is, the text was deconstructed and then reconstructed. 


\section{Results and Discussion}

\section{Overview of Findings}

This research aimed to develop a theory of why people present different attitudes toward different types of animal use. It was found that attitudes varied and were mediated by a combination of factors: (a) attitudes toward animals, (b) knowledge of animal use procedures, (c) whether the perceived benefits of using animals outweighed the perceived costs, and (d) whether there was a choice other than using animals (Table 1).

\section{Table 1 about here}

Summarizing the results, participants in the present study showed least support for using animals for entertainment and for personal decoration and most support for medical research and in teaching (dissection). This reflected our earlier findings (Knight et al., 2003). Animal use was most likely to be supported when participants perceived there to be no choice other than using animals, when little was known about animal use procedures, when liking for animals was low, and when the benefits of using animals were perceived to outweigh the costs.

Support for entertainment and personal decoration was low, as these uses were seen as unnecessary, that is, participants believed that there is no need to use animals for entertainment and that there are alternatives to using animals for personal decoration ( cruelty-free cosmetics and fake fur). Thus, participants believed that humans have a choice in terms of using animals for entertainment and personal decoration: These uses were perceived to be frivolous and unnecessary. However, when it came to discussing using animals in research and in teaching, participants thought the benefits of these to be so great that using animals was our only choice.

Moreover, participants could seldom think of replacements for animals in research and in teaching and so again believed that there was little choice other than using animals. Knowledge of animal use procedures also influenced attitudes, with more knowledge leading to reduced support for animal use. Furthermore, the benefits of using animals for research and teaching often were perceived to far outweigh the costs, although this was seldom the case for more "trivial" uses such as entertainment and personal decoration. Figure 1 presents a model that brings together the themes that emerged from this study, representing how people theorize about their views on animal use.

\section{Figure 1 about here}


The model illustrates that when people are thinking about their views on animal use, personal factors that can vary between people (such as what people know about animals and animal use) influence cognitive processing (in terms of cost-benefit analysis and perceptions of choice). Different personal factors and the varying impact of these may help to explain why different people hold different views toward different types of animal use. If a person (a) believes that animals are capable of experiencing pain and suffering ("knowledge of animals"), (b) believes that there are alternatives to using animals in research ("knowledge of animal use”), and (c) has a positive attitude toward animals ("attitudes toward animals"), then these factors will influence cognitive processing (both "cost-benefit analysis" and "perceptions of choice"), and that person will be less supportive of using animals for research.

It is important, however, to note that this model (Figure 1) is fluid. Thus, rather than people considering the "facts" and then forming an attitude based on these factors, it seems that people often work backward. Although they like animals, they also eat meat and, therefore, need to justify this contradictory behavior. Thus, they "build” their argument to justify their existing view or behavior, rather than forming an attitude based on the arguments. Therefore, information is actively sought after, or actively avoided, depending on whether it supports or undermines the existing attitude or behavior. This is of psychological importance. Future research using quantitative methods may now test this model in terms of examining the direction and strength of relationships between themes, how much impact each of these factors has on attitudes toward animal use, and which are most influential. Knowledge of this may give some indication of how attitudes may be changed and thus may be useful to scientists seeking support for their work or animal welfare workers trying to increase support for the humane treatment of animals.

Each theme now is described in detail, and excerpts from the transcripts are used throughout to enhance understanding and to demonstrate that the developing theory remained grounded in the data. Each quotation is followed by information that can enable the excerpt to be traced ( $\mathrm{P}$ followed by a number represents participant number, $\mathrm{L}$ followed by numbers represent line number in text).

\section{Attitudes Toward Animals}

How participants feel about animals was clearly central to how they felt about animal use, in that the more participants liked animals, the less they supported animal use (and vice versa).

'so, um, it [animal use] is a classic moral dilemma if you like animals and don't want them to suffer. (P1, L79-80)

Underlying attitudes toward animals was a perceived knowledge of animals, in terms of belief in animal mind (BAM), and physical characteristics of animals.

\section{Belief in Animal Mind (BAM)}


All participants discussed the mental abilities of animals, and none seemed to doubt the existence of animal mind.

I find it very hard to believe that a complex, living, breathing, animal of any sort -- human or otherwise -- can't think and feel, it seems a bit strange to me. (P9, L294-296)

However, while participants clearly believed in animal mind, they also discussed how as humans we cannot know what goes on in these minds. Thus, animal minds are considered somehow different from human minds.

I don't know any more than that because none of us know what goes on in the minds of animals.

(P5, L108-109)

Moreover, not only were animal minds perceived to be different from that of humans, all participants expressed the belief that animal mind is different for different species of animals. For example, they believed that although virtually all animals are capable of some kind of basic mental activity, belief in "higher" mental functions was reserved for only particular species of animals such as chimpanzees and apes.

I mean I would draw the distinction between different sort of animals- I think a great many animals would feel pain, but only a relatively small number of species would have the ability, I suspect, to reason and think things through, and operate as social animals, but some certainly can. (P5, L110-114)

There was a clear relationship between BAM and attitudes toward animal use, in that animal use was perceived as more acceptable when animals were believed to be lacking in mental ability. This allowed participants somehow to avoid personal conflict between, on one hand, their affection for animals and, on the other, their support for animal use.

I think it serves a purpose for us to believe animals don’t think and feel....Because that creates so many other issues about the way we treat them, for food or whatever. (P7, L307-310)

I think it's that [instinct] that guides animals rather than intelligence. I don't believe it's true intelligence- I hope it’s not- I wouldn’t like that [pheasant shooting] if it was. (P5, L195-197)

Indeed, two participants involved in hunting said that they would not hunt certain animals if they believed they were mentally capable.

I don't think they [foxes] do [have intelligence], but if I did I think that would put me off [hunting]. (P3, L187-188)

Certainly for the higher mammals, I do have a problem there. I mean, if there was a chimpanzee shoot, you wouldn't get me along. (P6, L487-489)

These findings support previous research that suggested attitudes toward animal use relate to BAM, concerning the animals' similarity to humans in terms of mental ability (Allen et al., 2002) and their 
capacity to experience pain and suffering (Herzog \& Galvin, 1997). Plous (1993) called this a "hierarchy of privilege" assigned to species, with primates and pet animals occupying the most privileged positions. BAM may, therefore, be a mechanism that enables people to avoid uncomfortable thoughts and feelings when faced with a dissonance between their liking of animals and their use of animals.

\section{Physical Characteristics of Animals}

Physical characteristics of animals related to liking animals. This also influenced attitudes toward animal use. Participants preferred animals who were perceived as more physically similar to humans, and support for the use of these types of animals was low. Also, if animals were perceived to be more similar physically to humans, this led to beliefs that they are more similar mentally to humans.

People are most emotional about things with two eyes, a nose, and a mouth on the front of the face... But the further you go down, the uglier the animal is, the smaller it is, the less like a mammal it is- the less they seem to be compassionate about it. And I think, yeah, if it’s got 2 eyes, a nose and a mouth, most of that is in the front of its head, it gets far more compassion than if it has 6 legs, crawls about and has eyes... 8 eyes, hairy legs, and a little body- then no compassion at all. (P4, L136-146)

So it then becomes an anthropomorphic decision, as to, it's got a brain, a backbone, it's got eyes, nose, a face -- must be more intelligent, must be more, must feel pain. (P4, L258-260)

Also, the more attractive and appealing animals were perceived to be, the more animals were liked and the less likely participants were to support use of that animal.

And I think also, animals that look appealing have an effect -- like dolphins, I think everyone would be appalled if they started hunting dolphins. (P6, L490-492)

The "similarity effect" describes how "people give more consideration to others who are perceived as similar to themselves than to those perceived as dissimilar” (Plous, 1993, p. 32). This effect can be generalized to animals (Allen et al., 2002) and would explain why people do not support the use of animals who are perceived as more similar to humans, either physically, mentally, or both. Animals perceived to be less similar also can be subjected to ingroup-outgroup biases (Plous), which leads to negative evaluation of the outgroup members and an over-estimation of between group differences (Tajfel, 1970). Thus, if animals are seen as outgroup members, their mental capacities may be underestimated. Although animals experience pain in a similar way to humans (Hoff, 1980), people continue to believe that animals do not feel pain in order to defend their use of animals (Herzog \& Galvin, 1997). If assigning animals as members of an outgroup is one mechanism for allowing animal use to continue, then psychological research on intergroup relations may help us to understand more about this topic.

\section{Knowledge of Animal Use Procedures}


Views on animal use were often discussed in terms of what participants knew about animal use (i.e., what actually happens to animals who are "used"). Participants expressed different levels of knowledge about different types of animal use, with least known about using animals in medical research.

I'm sure I would be shocked by quite a lot of things if I did know more about it [animal experimentation], but I don't. (P5, L245-256)

I don't know enough about experimenting on animals to comment really. I don't know enough to say what is right or wrong. (P3, L112-114)

Thus, participants were unlikely to oppose research because of animal use procedures because they actually knew very little about these procedures. Furthermore, most participants claimed that they didn't know about the procedures because they didn't want to know. Participants talked about avoiding information concerning animal use because it led to unpleasant feelings of discomfort.

I would rather not know.... I don’t make it my business to know, so I suppose that implies that I would rather not know, yeah..... And when I'm exposed to the facts, like probably a lot of people I recoil a bit, a bit horrified about it -- like oh my god, you know. But so maybe there's a denial of, to an extent, of what goes on, because obviously from time-to-time you read about things and think- that's not very nice, you know. (P2, L135-143)

That participants often stressed that they didn't want to know about animal use, may be because avoidance of animal use (veganism) requires effort and can lead to psychological, physical, and social difficulties for people choosing this option (McDonald, 2000). Change is likely to be challenging. Thus, dissociation -- avoiding knowledge of animal use, or repression, in terms of somehow failing to remember such knowledge -- are often the preferred options. Indeed, McDonald stated: "Repression may be a key factor in why many individuals hear about animal cruelty but do not act” (p19). However, we would argue that the process of avoiding information is less of a form of repression and more a deliberate strategy developed to manage emotion and justify behavior.

Uncomfortable feelings, caused by knowledge of how animals are used, were also discussed in terms of feeling helpless.

I think with so many of these issues you think well, you feel so helpless, I mean eating meat-

what difference does one person giving up meat have? (P9, L49-51)

Other participants discussed their feelings toward knowledge of animal use in terms of personal relevance.

And no, I didn't like to see that kind of animal being used in that kind of way, but if there was a cure for cancer and it affected me personally, I guess I'd have to think some more. (P9, L22-24) Thus, it appears that views may be fluid according to how personally relevant animal use is to each individual. 
Knowledge occasionally led to outright rejection of animal use practices because participants perceived these to be so unpleasant for animals. Several participants discussed seeing pictures of chemicals being injected into animals eyes during cosmetics testing. Research has found that students who are more likely to encounter animal experimentation in their academic career (students of biology and medicine), are more likely to oppose animal research than are other students (Broida, Tingley, Kimball, \& Miele, 1993). Science students, compared to non-science students (Sieber, 1986), are more likely to propose a need for improvement of animal research procedures. Thus, it may be to the advantage of medical research to keep information about animal use procedures from the public, because it seems that knowledge leads to reduced support for such practices. Future research may examine whether students who experienced animal use procedures in their studies are over-represented within animal activist organizations.

\section{Cost-Benefit Analysis}

Participant often weighed up the costs of animal use versus the benefits when rationalizing how they could hold different attitudes toward different types of animal use.

I think it, personally, if you're asking me, yes I think it [animal use] should be weighed up, I think it should be evaluated, the potential benefits against the potential suffering of an animal. (P2, L76-78)

But, it [animal experimentation] seems different from, like, dog fighting or badger baiting, or something like this, that, if it was, well- there's some cure for cancer, or there's some kind of specific thing, one might argue that there was a qualitative difference in the moral justification of it, I suppose. (P3, L22-24)

It seems, “The most persuasive argument for using animals in behavioral research, however, is the untold benefit that accrues to both humans and animals” (Baldwin, 1993, p. 123). However, participants admitted to knowing little about the costs (distress caused to animals) and perhaps more important, did not want to know (see "Knowledge of Animal Use Procedures” above). Thus, the process of cost-benefit analysis is not always a fair and logical assessment of the pros versus the cons of animal use.

Participants often discussed animal use in relation to their moral beliefs weighing up the rights of the individual animals being used against the possible outcome of finding a cure that could help countless humans. Others expressed how it would be morally wrong not to use animals if cures for disease such as cancers could be the result.

And there's an ethical principle that, yeah -- it does raise questions about -- does the animal want to be involved in saving the human race, you know. (P12, L78-81)

...or if there's a cure to cancer that can be found through using animals then it would be morally wrong not to go down that road. (P4, L51-53) 
Previous research has found that support for vivisection increases depending on its perceived utility for humans (Braithwaite \& Braithwaite, 1982; Tamir \& Hamo, 1980) and that people agree with research that causes pain and injury on animals if it is said to provide new information about human health problems (Pifer et al., 1994). Many people practice moral decision making by comparing the suffering of animals to the benefits to humankind (Wuensch, Jenkins, \& Poteat, 2002). Advocates of animal research argue that animal suffering is small compared to the resulting benefits to humankind (Miller, 1985). Thus, it seems that animal suffering is perceived as less important than human suffering. In the present study, the purpose of research clearly was important to participants discussing their views on animal experimentation and is consistent with the views of others (Baldwin, 1993; Pifer et al., 1994). However, this may not be the case with misanthropes (people who do not like humans), who are unlikely to see benefits to humans as outweighing the costs of animal suffering (Wuensch et al., 2002). Future research may examine how personality characteristics such as misanthropy, philanthropy, and idealism influence how people theorize about animal use.

\section{Perceptions of Choice}

This theme described how participants discussed whether we have a choice other than using animals and was a central theme mentioned by all participants. This supports existing research that found a factor important in relation to attitudes toward animal experimentation is the necessity of medical research (Pifer, et al., 1994).

Participants seemed to be asking three questions when exploring the concept of choice: "Is animal use necessary?” "How are animals treated?” "Is animal use natural?” Each of these questions will now be addressed.

\section{Is Animal Use Necessary?}

Often, participants justified animal use by saying that the benefits so far outweighed the costs of using animals that we have no choice other than to use animals (when medical research is seeking a cure for cancer). Furthermore, animal use was deemed necessary if there were no alternatives to using animals. Although participants were aware of cruelty-free cosmetics (i.e. not tested on animals), they rarely could think of a replacement for animals that medical research could use. Thus, support was lower for the former and higher for the latter.

Yes, it's possible, faced with a situation and if you were to weight the whole matrix of how the animal is used and feels, and what the importance of the research is, yes, you would probably end up with reasons for using animals where the research can only be done, and it's crucial to technology advances, and those sorts of things. (P8, L43-45)

Well anything, if it's a living, breathing thing, human or animal, it doesn't feel right to be putting it through pain just to prove something if there is an alternative. (P10, L15-18) 
However, if uses were perceived as unnecessary in themselves, that is, their outcomes were of no great consequence or frivolous, then participants thought that we do have a choice and thus should choose not to use animals in this way.

Certainly for entertainment, for decoration, for financial gain, definitely not -- there are alternatives. And there's no way you can justify using animals for the vanity of humans- so for make-up, cosmetics, etc. (P9, L37-40)

Although many participants stated that we should not stop using animals in medical research, they also expressed that time and effort should be spent seeking alternatives and that repetition or duplication was unnecessary.

... or more time should be spent on seeking other ways of doing the research. (P8, L48-49) Clearly, a perceived lack of alternatives was one underlying reason why people are more supportive of using animals in research. Although previous research has found that biology students prefer such alternatives to dissecting real animals (Kinzie, Larsen, Birch, \& Boker, 1996), some students believe dissection is the only way to appreciate the intricacies of the body. Further, biology teachers perceive computer-based alternatives to be unacceptable (Barr \& Herzog, 2000).

\section{How Are Animals Treated?}

Often, participants made clear that although they accepted that animals had to be used in some ways, they considered it important that animals are treated and killed humanely.

But I do think that farming can be done in a humane way, and should be done in a humane way.

And I do believe that we can give animals a reasonable life, and you can kill them humanely, quickly, painlessly, without too much distress, and I think you should always endeavor to do that. (P15, L84-88)

Thus, participants believed we have a choice as to how we treat and kill animals and that we should choose to be as humane as possible.

Indeed, attitudes toward animal use do differ according to the amount of pain that the animal is perceived to endure (Miller, 1992; Rajecki, Rasmussen, \& Craft, 1993), and people who support research often seek assurance that animals are treated humanely (Baldwin, 1993). However, others found that participants would support research proposed to cause pain and injury on animals when the research might provide new information about human health problems (Pifer, Shimizu, \& Pifer, 1994). Thus, it seems that if the outcome of research relates to medical progress, then this outweighs the costs in terms of animal pain and discomfort. Further, although people are against animal use that involves animal pain and discomfort (they disapprove of "the use of inhumane killing at an abattoir"), their behavior may contradict this view: They do not disapprove of "eating meat from an abattoir which uses inhumane methods of killing” (Braithwaite \& Braithwaite, 1982). The reality is that animals cannot always be treated or killed 
humanely -- animal use inevitably will cause suffering (Serjeant, 1969). Moreover, products such as freerange and organically farmed animal meat take up a small amount of supermarket shelf space, indicating that although people may say that they want animals to be treated and killed humanely, they do not reflect these views in their behavior by buying these types of cruelty-free animal products.

\section{Is Animal Use Natural?}

Participants often described the use of animals as natural, implying that humans have no choice other than using animals. In terms of man's instinct to hunt, kill, and eat animals,

We haven’t got the teeth for vegetarians; our make-up makes us meat-eaters, doesn’t it? (P14,

This allows us to take less responsibility for participation in animal use if we are "controlled" by our natural instinct. Although this idea may seem an outdated view in this day and age, Herzog (2002) described how for most of human history men have lived as hunter-gatherers and thus, "Our modern skulls house a stone-age mind" (Cosmides \& Tooby, 1997, cited in Herzog, 2002, p. 361). However, we might argue that we are more than this because humans clearly show evidence of moral reasoning. Thus, using our natural instinct as a reason for animal use may be a convenient excuse that would not hold up to empirical scrutiny (many humans do abstain from eating meat and therefore are not "controlled" by their instinct).

Similarly, participants described how we treat animals within the context of the circle of life. Animal use was seen as a natural behavior as part of our place in this circle, and participants justified this further by emphasizing how animals behave with each other.

And I think within a man that hunter -- I think the hunting instinct’s there, I really do, I think it just goes back right to the times of old, and it is in them, it's in their blood to do it, just as much as it's in my blood to do womanly things it's in their blood to do the manly things, and that's one of them. (P3, L139-144)

...but I must say, I am a meat eater, I am a carnivore. I keep on feeling my incisors, we've got the incisors for cutting meat, we've got canines for tearing meat, so, if you look at our other primates, like chimps, they eat other monkeys, don't they? They go off, and get some meat. (P1, L412-417) Thus, by comparing human behavior to animal behavior, our own behavior seems reasonable. Further, the notion of eating meat as a natural instinct may relieve us of any guilt that may come from eating animals. It may be a psychological mechanism that reduces personal conflict (Plous, 1993). Such ideas also may be deeply ingrained within our culture (Griffith, Wolch, \& Lassiter, 2002). So, cultural norms can enable us to believe that we have no alternative other than to eat meat because that is what nature intended. Indeed, Plous found that children are taught that eating meat is necessary for adequate nutrition, although animal- 
based diets can be unhealthy. It is, therefore, not surprising that people use this as justification for animal use.

\section{Ideas for Future Research}

The findings from this research raise many interesting questions that may form the basis for further research. How do people who support and/or practice animal use avoid discomfort when faced with an animal who clearly is suffering as a result of this practice? Thus, future research should include people with scientific knowledge of animal experimentation issues and those actively involved in animal use.

Findings of this research also may relate to attitudinal research on a wider, theoretical level. How are the themes that emerged from discussing attitudes toward animal use similar to those underlying views toward other attitude objects? Three of our four themes (knowledge of animal use, perceptions of choice, and cost-benefit analysis) are similar to those found to emerge from discussions with parents concerning their views on the combined MMR (measles, mumps, rubella) vaccine for children (Buckley, 2002). Thus, similar cognitive processes may be at work when people are considering their views on issues other than animal use.

\section{A Reflection on the Methodology Used in This Study}

Herzog (1993) proposed that it is usual in qualitative research for researchers to describe their personal perspective and potential biases. Although I am fond of animals, my stance (first author) is, I find it hard to oppose certain types of animal use such as medical research that seeks to find cures for serious diseases. Thus, I am aware this is a paradox I may share with participants and that my views may impinge on my interpretations of the data. Indeed, in the free-flowing dialogues of in-depth exploration of inductive Grounded Theory interviews, it is hard to see how my own position always is hidden from the participants, and this may constitute a conceptual problem for Grounded Theory methodology. In practice, the interviewer is engaged in an interaction with the interviewee, and the interviewer is not in a position to extract pristine and untainted data from the interviewee. However, the aim of this study is to search for the theories of participants, not to seek the confirmation or rejection of an existing theory on animal use. In a serious sense, I have tried to avoid imposing my personal theory on participants during interviews and later during analysis.

\section{Conclusions}

Animal use is often described as natural, necessary, inevitable (Plous, 1993); yet, people are naïve about animal use. They don't know and -- more important -- don't want to know about the sometimes unpleasant procedures involved in animal use. Further investigation is needed that focuses on people's motivation to maintain an attitude or behavior and examines the underlying processing of factors relating to the animal and type of use, rather than trying to explain attitude variance in terms of personal variables 
such as gender and age. By acknowledging this, we may develop a more rounded and more detailed understanding of people's views on how animals are used.

\title{
Note
}

\begin{abstract}
${ }^{1}$ Correspondence should be sent to Sarah Knight, University of Portsmouth, Department of Psychology, King Henry Building, King Henry Street, Portsmouth, UK PO1 2DY. E-mail: sarah.knight@port.ac.uk

${ }^{2}$ The use of questionnaires prior to qualitative interviews may be seen as inappropriate, and thus we must accept the possibility that this may have an impact on our findings. However, a similar combination of methodologies have been used previously (e.g. Buckley, 2002; Koch, 2001; Page, 1993), and furthermore, we suggest that contamination is minimized since the two different methodologies aimed to address different aspects of peoples' thinking. That is, the questionnaire measured attitudes towards animal use, whilst the interviews asked why people have different attitudes for different types of animal use.
\end{abstract}

\section{References}

Armstrong, J. B., \& Hutchins, M. E. (1996). Development of an attitude scale to measure attitudes toward humans’ use of nonhuman animals. Perceptual and Motor Skills, 82, 1003-1010.

Bauer, M. W., Gaskell, G., \& Allum, N. C. (2002). Quality, quantity and knowledge interests: Avoiding confusions. In M. W. Bauer \& G. Gaskell (Eds.), Qualitative researching with text, image and sound. London: Sage.

Braithwaite, J., \& Braithwaite, V. (1982). Attitudes toward animal suffering: An exploratory study. International Journal for the Study of Animal Problems, 3, 42-49.

Broida, J. Tingley, L. Kimball, R., \& Miele, J. (1993). Personality differences between pro- and antivivisectionists. Society \& Animals, 1, 129-144.

Buckley, E. (2002). Parents' attitudes toward the combined MMR vaccine: A brief qualitative analysis. PsyPAG Quarterly, 45, 55-63.

Crosby, F., Bromley, S., \& Saxe, L. (1980). Recent unobtrusive studies of black and white discrimination and prejudice: A literature review. Psychological Bulletin, 87, 546-563.

Driscoll, J. W. (1992). Attitudes Toward Animal Use. Anthrozoös, 5, 32-39.

Furnham, A., \& Pinder, A. (1990). Young people’s attitudes to experimentation on animals. The Psychologist, October, 444-448.

Glaser, B. G., \& Strauss, A. L. (1967). The discovery of grounded theory: strategies for qualitative research. New York: Aldine.

Griffith, M., Wolch, J., \& Lassiter, U. (2002). Animal practices and the racialization of Filipinas in Los Angeles. Society and Animals, 10, 221-248.

Herzog, H. A. (1993). "The movement is my life": The psychology of animal rights activism. Journal of Social Issues, 49, 103-119. 
Herzog, H. A., \& Galvin, S. (1997). Common sense and the mental lives of animals: An empirical approach. In R. W. Mitchell (Ed.), Anthropomorphism, anecdotes and animals. Albany: State University of New York Press.

Hills, A. M. (1995). Empathy and belief in the mental experience of animals. Reviews and research reports. Anthrozoös, 8, 132-142.

Kellert, S. R., \& Berry, J. K. (1981). Knowledge, affection and basic attitudes toward animals in American society. Springfield, VA.: National Technical Information Service, PB-81-173106.

Knight, S. E., Vrij, A., Cherryman, J., \& Nunkoosing, K.. (2003). The effect of belief in animal mind and other individual differences on attitudes toward animal use. (Submitted for publication in March 2003 to Personality \& Individual Differences).

Koch, L. C. (2001). The preferences and anticipations of people referred for vocational rehabilitation. Rehabilitation Counselling Bulletin, 44, 76-86.

LaPiere, R. T. (1934). Attitudes versus actions. Social Force, 13, 230-237.

Matthews, S. \& Herzog, H. A. (1997). Personality and attitudes toward the treatment of animals. Society \& Animals, 5, 169-175.

Nunkoosing, K., \& Phillips, D. (1999). Supporting families in the early education of children with special needs: the perspectives of Portage home visitors. European Journal of Special Needs Education, 14, 198211.

Page, J. M. (1993). Ethnic identity in dear Hispanics of New Mexico. Sign Language Studies, 80, 185222.

Patton, M. Q. (1990). Qualitative evaluation research methods. Newbury Park, CA: Sage.

Pifer, L., Shimizu, K., \& Pifer, R. (1994). Public attitudes toward public research: Some international comparisons. Society \& Animals, 2, 95-113.

Plous, S. (1993). Psychological mechanisms in the Human Use of Animals. Journal of Social Issues, 49, 11-52.

Rennie, D. L., Phillips, J. R., \& Quartaro, G. K. (1988). Grounded Theory: A promising approach to conceptualisation in psychology. Canadian Psychology, 29, 139-150.

Serjeant, R. (1969). The spectrum of pain. London: Rupert Hart-Davis.

Strauss, A., \& Corbin, J. (1991). Basics of qualitative research: grounded theory procedures and techniques. Newbury Park: Sage.

Turner, B. A. (1981). Some practical aspects of qualitative data analysis: one way of organising the cognitive processes associated with the generation of grounded theory. Quality and Quantity, 15, 225247. 
Table 1: Themes Used by Participants to Explain Different Attitudes Toward Different Types of Animal Use.

\begin{tabular}{ll}
\hline \multicolumn{1}{l}{ Themes } & Properties \\
\hline $1 \quad$ ATTITUDES TOWARD & Knowledge of animals \\
ANIMALS & (BAM and physical characteristics)
\end{tabular}

2 KNOWLEDGE OF

ANIMAL USE

PROCEDURES

3 COST-BENEFIT

ANALYSIS

4 PERCEPTIONS OF

CHOICE
Knowing about animal use

Knowing about alternatives

Not wanting to know

Animal use for human health benefits

Animal use for animal health benefits

Animal use as a moral issue

Is animal use necessary?

How are animals treated?

Is animal use natural? 
Figure 1. Attitudes Toward Animal Use: A Model

\begin{tabular}{|l|l|l|l|}
\hline \multicolumn{3}{|l|}{ Personal factors, experience and understanding } \\
\hline $\begin{array}{l}\text { Individual } \\
\text { differences }\end{array}$ & $\begin{array}{l}\text { Attitudes toward } \\
\text { animals }\end{array}$ & $\begin{array}{l}\text { Knowledge of } \\
\text { animals }\end{array}$ & $\begin{array}{l}\text { Knowledge of } \\
\text { animal use }\end{array}$ \\
\hline \hline \multicolumn{3}{|l|}{$\uparrow$} & \\
\hline Cognitive processing & Perceptions of choice \\
\hline
\end{tabular}

